\title{
Robotic adrenalectomy in patients with pheochromocytoma: a systematic review
}

\author{
Florence Bihain $^{1}$, Marc Klein ${ }^{2}$, Claire Nomine-Criqui ${ }^{1}$, Laurent Brunaud ${ }^{1}$ \\ ${ }^{1}$ Département de Chirurgie Viscérale, Métabolique et Cancérologique (CVMC), ${ }^{2}$ Service d'Endocrinologie, Diabétologie et Nutrition, Unité \\ multidisciplinaire de chirurgie métabolique, endocrinienne et thyroïdienne (UMET), CHRU Brabois, Université de Lorraine, Nancy, France \\ Contributions: (I) Conception and design: M Klein, L Brunaud; (II) Administrative support: M Klein, L Brunaud; (III) Provision of study materials \\ or patients: M Klein, C Nomine-Criqui, L Brunaud; (IV) Collection and assembly of data: F Bihain, C Nomine-Criqui; (V) Data analysis and \\ interpretation: F Bihain, C Nomine-Criqui, L Brunaud; (VI) Manuscript writing: All authors; (VII) Final approval of manuscript: All authors. \\ Correspondence to: Laurent Brunaud. Département de Chirurgie Viscérale, Métabolique et Cancérologique (CVMC), Unité multidisciplinaire de chirurgie \\ métabolique, endocrinienne et thyrö̈dienne (UMET), CHRU Brabois, Université de Lorraine, Nancy, France. Email: 1.brunaud@chru-nancy.fr.
}

\begin{abstract}
Pheochromocytomas (PHEOs) are neural crest cell tumors producing catecholamines. PHEOS need to be early diagnosed and adequately managed. Adrenalectomy is the gold standard treatment of these type of tumors. There has been major improvement of surgical technologies with the development of laparoscopic and robotic systems these past several years. We conducted a review of the literature to evaluate the robotic approach for adrenalectomy for patients with PHEO.
\end{abstract}

Keywords: Pheochromocytoma; adrenalectomy; robotics; laparoscopy; morbidity; hemodynamic instability

Submitted Dec 31, 2019. Accepted for publication May 28, 2020.

doi: 10.21037 /gs-2019-ra-05

View this article at: http://dx.doi.org/10.21037/gs-2019-ra-05

\section{Introduction}

Pheochromocytoma (PHEO) is a rare catecholamine producing neuroendocrine tumor that can be adrenal or extra adrenal in its origin. It manifests itself by various symptoms such as sweating, headaches, palpitations and hypertension. The estimated incidence of PHEO ranges from $0.05 \%$ to $0.1 \%$ in the general population. However, it is higher in the hypertensive population (1). PHEO occurs mostly in young patients (40-50 years old) with a slight predilection for women and is diagnosed by measuring elevated levels of metanephrines (catecholamine metabolites) in blood or urine. Then when a biochemical diagnostic is set, imaging techniques such as CT or MRI are used to localize the adrenal tumor(s). CT and MRI have a high sensitivity (between 93-100\%), but they lack specificity (50-90\%), implicating various false negatives (2). Thus, the use of functional imaging using MIBG scintigraphy and/or DOPA PET is a relevant tool to diagnose an localize PHEOs.

Adrenalectomy is the gold standard treatment of PHEOs. Several different techniques of adrenalectomy have been described: open transperitoneal adrenalectomy, laparoscopic lateral transperitoneal adrenalectomy, posterior retroperitoneal adrenalectomy and robotic surgery. Open transperitoneal adrenalectomy has been considered for a long time as the gold standard when treating adrenal diseases. However, since the 1990's, laparoscopic and robotic techniques have emerged and replaced open approaches. In 2020, almost all PHEOs can be resected using a laparoscopic and/or robotic approach, while laparotomy remains to be used in large or malignant tumors with adjacent organs invasion. The goal of this manuscript was to review all available studies evaluating the use of the robotic system to perform an adrenalectomy when treating patients with PHEO.

\section{Methods}

A systematic review using PubMed database was used to search for relevant English language studies comparing laparoscopic to robotic adrenalectomy (RA) in patients with PHEO. We also searched for articles addressing the 
specificities of treating PHEOs. One author independently searched the literature on November $3^{\text {rd }}, 2019$ for pertinent studies using several keywords such as "robotic", "pheochromocytoma", "laparoscopic". We excluded case reports, articles not focused on surgical management and articles that had less than 5 patients. A total of 21 articles met our inclusion criteria. The principles of Helsinki declaration were followed in this review

\section{$R A$ versus laparoscopic adrenalectomy $(L A)$ : feasibility and safety}

The robotic system was first introduced for cardiac surgeries in the late nineties. It has since expanded its use to many other types of surgeries including adrenalectomies. Robotic technology increases surgeon's control, has a superior instrument dexterity, wristed articulation and a $3 \mathrm{D}$ visualization.

Several articles in the literature demonstrate that RA is as feasible and safe than RA.

It was shown that there was a need to perform 20 cases to obtain a similar outcome than with a laparoscopic approach (3). This means that after a learning curve of 20 robotic cases there is no difference as regards to operative time between the RA group and the LA group. This study also demonstrated that the robotic system was an advantage in certain specific situations such as in obese patients and patients with larger tumors $(>55 \mathrm{~mm})$. Karabulut et al. supported these findings in their study: intraoperative time was similar in their study when comparing LA and RA, whereas the tumor's volume was larger for the robotic approach (4).

As regards to operating time, studies tend to have conflicting results. Indeed, Brunaud et al. and Morino et al. showed that there was a longer operative time when using the robot compared to the laparoscopic approach $(3,5)$. However, these findings tend to be put in perspective since several other studies did not have the same results. Indeed, several studies did not find a significant difference between RA and LA as regards of operative time $(4,6,7)$. Furthermore, Greilsamer et al. showed in a recent prospective study, including 303 patients, that mean operative time decreased from 99 to $77 \mathrm{~min}(\mathrm{P}<0.001)$ between the first and last 100 patients. Studies since 2012 have not shown a significant difference as concerns of operative time between RA and LA, and moreover, recent studies suggest a lesser operative time than earlier studies on this matter and a decrease of operative time with experience. This could suggest that with the widespread use of the robot and robotic experience, it seems to be no difference between RA and LA.

There is no unique complication related to a robotic approach. In Chai et al. systematic review regrouping 6 studies, there was no particular complication directly associated with the use of the robot (8). Based on the available data to this day, we can solely affirm that there is no difference in terms of mortality or morbidity between RA and LA.

To sum up, robotic surgery is as safe and feasible than a laparoscopic procedure. However, because of its financial burden for the hospital and its long training process, the value of robotic system needs to be put in perspective when performing operations that are already performed safely and rapidly with a laparoscopic approach.

\section{$R A$ and PHEO}

There is limited data on the use of the robotic system in patients with PHEO. We only found one study with a prospective database analyzed retrospectively. Indeed, Aliyev et al. (9) conducted a study comparing perioperative outcomes and the efficacy of RA versus RA for PHEOs. In this study, 25 patients underwent $26 \mathrm{RA}$, and 40 patients underwent 42 LA procedures for PHEO. They compared blood loss, operative time, tumor size and intraoperative hemodynamic parameters. There was no difference in terms of blood loss, and intraoperative hemodynamic parameters. Furthermore, there was a lower pain score on postoperative day 1 and a shorter hospital stay in the RA group, and it seemed there was an advantage with the use of the robotic system regarding operative time. There were no significant differences in terms of morbidity and mortality between the two groups. Nonetheless, there were several limitations to that study including the nonrandomized design and the sample size. To establish to role of robotic surgery in patients with PHEO there is a need to conceive prospective randomized studies in larger population (Table 1).

\section{Robot-assisted laparoscopic partial or total adrenalectomy for PHEO?}

The traditional surgical treatment of PHEO is total adrenalectomy. However, in the recent years, adrenal sparing surgery has increased to avoid side effects of adrenal insufficiency and steroid replacement. Indeed, some adrenal tumors can be bilateral, such as in hereditary syndromes. 
Table 1 Comparison of perioperative outcomes between RA and LA for patients with adrenalectomies for pheochromocytoma

\begin{tabular}{|c|c|c|c|c|c|c|c|c|c|c|c|c|c|c|}
\hline Variable & \multicolumn{2}{|c|}{ Operative time } & \multicolumn{2}{|c|}{$\mathrm{EBL}(\mathrm{mL})$} & \multicolumn{2}{|c|}{ Conversion } & \multicolumn{2}{|c|}{ Complication } & \multicolumn{2}{|c|}{ Hospital stay } & \multicolumn{2}{|c|}{$\begin{array}{c}\text { Greatest } \\
\text { intraoperative BP } \\
\text { (mean) }\end{array}$} & \multicolumn{2}{|c|}{$\begin{array}{l}\text { Lowest intraoperative } \\
\text { BP (mean) }\end{array}$} \\
\hline Aliyev 2013 & 178 & 149 & 43 & 36 & 3 & 1 & 4 & 0 & 1,7 & 1,2 & 132 & 127 & 77 & 75 \\
\hline Gupa 2014 & 176 & 161 & 176 & 92 & NA & NA & NA & NA & NA & NA & NA & NA & NA & NA \\
\hline
\end{tabular}

RA, robotic adrenalectomy; LA, laparoscopic adrenalectomy; EBL, estimated blood loss; NA, non available data.

Treatment of these bilateral masses would be total bilateral adrenalectomy and would result in life-long steroid supplementation. To avoid this life-long supplementation which is not exempt of sides effects and the risk of potential adrenal insufficiency, adrenal sparing surgery has expanded. And thus, this trend of partial adrenalectomy has also spread to those with a normal contralateral gland supported by the benefits it carries.

Kaye et al. in their systematic review of partial adrenalectomy outcomes, showed that adrenal sparing surgery is mostly done in Conn's disease, closely followed by PHEO (10). They state in that review that the position of the tumor is an important criterion for deciding whether to use an adrenal sparing approach. Still in this review, it was demonstrated that perioperative outcomes were similar in partial and total adrenalectomy.

Hereditary PHEO has a high recurrence rate with a multifocal nature. In Kaye's systematic review, there were no articles showing that partial adrenalectomies were unsafe to treat hereditary PHEO (10).

Gupta et al. evaluated in their 2014 study perioperative functional and short- term oncological outcomes of partial adrenalectomy in patients with multiple PHEO (11). They included 8 patients and performed 10 procedures for ipsilateral PHEOs. Of those 10 procedures, 6 were robot assisted and 4 by laparoscopy. There were no perioperative complications, and at follow-up at 12 months, every patient had resolution of their symptoms and only one required steroid replacement. However, these results need to be put in perspective: several limitations exist; it was again a retrospective study with a small population.

Asher et al. evaluated robot assisted laparoscopic partial adrenalectomies for PHEO (RALPA) (12). They performed 15 RALPA in 12 consecutive patients. Blood loss, tumor size, intraoperative hemodynamic parameters and operative time were reviewed. They recognize that technical considerations, such as the position of the patient on the operating table and the exposition of the adrenal glands, are crucial to correctly dissect the glands and there so put to use the advantage of the robotic approach during the resection of the tumor.

Concerning blood loss, operative time and hemodynamic parameters it was shown that these factors decreased with the robotic approach comparing to an open approach. This study has also several limitations: small sample, retrospective and the non-randomized design. Furthermore, there was no comparison between a robotic approach and a laparoscopic approach. This is why we can only affirm that minimally invasive surgical resection should be considered as a safe and feasible approach in patients with PHEO. There is a need to evaluate with large population prospective randomized studies the use of robot assisted technology in partial adrenalectomy versus laparoscopic partial adrenalectomy in patients with PHEO.

\section{Robotic approach and malignant PHEO}

Malignant PHEO is a rare catecholamine cancer deriving from chromaffin cells of the adrenal medulla (13). Surgical management of malignant $\mathrm{PHEO}$ consists of adrenalectomy or debulking surgery (14). There are different types of surgeries possible: open surgery, laparoscopic and robotic surgery. Goffredo et al. in their 2015 study, analyzed patterns of use of minimally invasive surgery (MIS) (laparoscopic and robotic surgeries) for malignant PHEOs in the United States and compared short term outcomes of MIS to open adrenalectomy. They observed no difference in the number of lymph nodes harvested, 30-day mortality or readmissions rates compared to the open surgery group (15). They also observed that malignant tumors were smaller in the MIS group. However, they collected their data on a large database, providing source to coding errors. 
They also could not discriminate the minimally invasive procedures: how did the robot influence this minimally invasive approach? Moreover, they only compared short term outcomes and further studies on long term outcomes and robotic use are required.

\section{Preoperative fluid and hypotensive drug administration}

Pre-operative blockade of alpha-1 receptors is increasingly employed in an attempt to reduce the risk of hypertensive episodes, especially during manipulation of the tumor (16). Operative resections carry a high intraoperative risk of releasing massively catecholamines into the blood circulation. It was shown that there are three perioperative phases that are associated with a high risk of hemodynamic instability: endotracheal intubation, creation of the pneumoperitoneum and manipulation of the adrenal gland $(16,17)$. Alpha adrenergic blockade has been routinely accepted as preoperative medical management to reduce intraoperative hemodynamic instability (18). Other regimen using calcium channel blockers or other medications for preoperative medical preparation have also been proposed more recently (16). However, the most vivid criticism regarding the routine use of preoperative medical preparation is that there is no longer a significant relationship between preinduction blood pressure normalization after preoperative medical preparation and post-operative morbidity (19). Indeed, Lentschener et al. condemned the lack of evidence based when proning preoperative medical management (20). Preoperative hypotensive drugs were first used in the late fifties. Golstein et al. observed from 1957 to 1996, in 108 PHEOs a decrease in complications from $69 \%$ to $3 \%$ with the use of alpha blockers (19). However, they did not incorporate the major surgical improvements (laparoscopy, preoperative localization, PET imaging) that occurred during that period and anesthetic management. A recent meta-analysis confirmed the lack of evidence for preoperative $\alpha$-blockade in surgery for phaeochromocytoma (21). It was shown in several studies the impact of robotic use in the precision of tumors' resections. With this new robotic technology that allows to have a superior instrumental dexterity, and so to be more precise in surgical dissections: how can the robot help surgeons and anesthesiologists manage intraoperative hemodynamic instability? More studies need to be performed to evaluate the role of a robotic approach in intraoperative hemodynamic instability episodes and postoperative complications. There has not yet any data on the role of the robotic approach and its utility as regards to the management of hemodynamic instability, this matter should be one of the major concerns going forward.

\section{Conclusions}

Introduction of robot technology has had a major impact on the surgeon's operating technique, with a better control and greater dexterity. Many studies have described the utility of the robot versus laparoscopic on adrenalectomies. However, there is a lack of articles when specifically addressing the subject on adrenalectomies for patients with PHEOs. Studies need to be performed to evaluate the use of the robot on performing adrenalectomies for patients with PHEO.

\section{Acknowledgments}

Funding: None.

\section{Footnote}

Provenance and Peer Review: This article was commissioned by the Guest Editor (Özer Makay) for the series "Robotic Adrenalectomy" published in Gland Surgery. The article was sent for external peer review organized by the Guest Editor and the editorial office.

Conflicts of Interest: All authors have completed the ICMJE uniform disclosure form (available at http://dx. doi. org/ gs-2019-ra-05). The series "Robotic Adrenalectomy"was commissioned by the editorial office without any funding or sponsorship. The authors have no other conflicts of interest to declare.

Ethical Statement: The authors are accountable for all aspects of the work in ensuring that questions related to the accuracy or integrity of any part of the work are appropriately investigated and resolved.

Open Access Statement: This is an Open Access article distributed in accordance with the Creative Commons Attribution-NonCommercial-NoDerivs 4.0 International License (CC BY-NC-ND 4.0), which permits the noncommercial replication and distribution of the article with the strict proviso that no changes or edits are made and the original work is properly cited (including links to both the formal publication through the relevant DOI and the license). See: https://creativecommons.org/licenses/by-nc-nd/4.0/. 


\section{References}

1. Farrugia FA, Martikos G, Tzanetis $P$, et al. Pheochromocytoma, diagnosis and treatment: Review of the literature. Endocr Regul 2017;51:168-81.

2. Ilias I, Divgi C, Pacak K. Current role of metaiodobenzylguanidine in the diagnosis of pheochromocytoma and medullary thyroid cancer. Semin Nucl Med 2011;41:364-8.

3. Brunaud L, Bresler L, Ayav A, et al. Robotic-assisted adrenalectomy: what advantages compared to lateral transperitoneal laparoscopic adrenalectomy? Am J Surg 2008;195:433-8.

4. Karabulut K, Agcaoglu O, Aliyev S, et al. Comparison of intraoperative time use and perioperative outcomes for robotic versus laparoscopic adrenalectomy. Surgery 2012;151:537-42.

5. Morino M, Benincà G, Giraudo G, et al. Robot-assisted vs laparoscopic adrenalectomy: A prospective randomized controlled trial. Surg Endosc 2004;18:1742-6.

6. Agcaoglu O, Aliyev S, Karabulut K, et al. Robotic vs laparoscopic posterior retroperitoneal adrenalectomy. Arch Surg 2012;147:272-5.

7. Azizian M, Khoshnam M, Najmaei N, et al. Visual servoing in medical robotics: a survey. Part I: endoscopic and direct vision imaging - techniques and applications Mahdi. Int J Med Robot 2014;10:263-74.

8. Chai YJ, Kwon H, Yu HW, et al. Systematic Review of Surgical Approaches for Adrenal Tumors: Lateral Transperitoneal versus Posterior Retroperitoneal and Laparoscopic versus Robotic Adrenalectomy. Int J Endocrinol 2014;2014:918346.

9. Aliyev S, Karabulut K, Agcaoglu O, et al. Robotic versus laparoscopic adrenalectomy for pheochromocytoma. Ann Surg Oncol 2013;20:4190-4.

10. Kaye DR, Storey BB, Pacak K, et al. Partial Adrenalectomy: Underused First Line Therapy for Small Adrenal Tumors. J Urol 2010;184:18-25.

11. Gupta GN, Benson JS, Ross MJ, et al. Perioperative, functional, and oncologic outcomes of partial adrenalectomy for multiple ipsilateral pheochromocytomas. J Endourol 2014;28:112-6.

12. Asher KP, Gupta GN, Boris RS, et al. Robot-assisted laparoscopic partial adrenalectomy for pheochromocytoma: The national cancer institute technique. Eur Urol 2011;60:118-24.

13. Harari A, Inabnet WB 3rd. Malignant pheochromocytoma: a review. Am J Surg 2011;201:700-8.

14. Scholz T, Eisenhofer G, Pacak K. Clinical review: current treatment of malignant pheochromocytoma. J Clin Endocrinol Metab 2007;92:1217-25.

15. Goffredo P, Adam MA, Thomas SM, et al. Patterns of Use and Short-Term Outcomes of Minimally Invasive Surgery for Malignant Pheochromocytoma: A Population-Level Study. World J Surg 2015;39:1966-73.

16. Brunaud L, Boutami M, Nguyen-Thi PL, et al. Both preoperative alpha and calcium channel blockade impact intraoperative hemodynamic stability similarly in the management of pheochromocytoma. Surgery 2014;156:1410-7; discussion 1417-8.

17. Bruynzeel H, Feelders RA, Groenland THN, et al. Risk Factors for Hemodynamic Instability during Surgery for Pheochromocytoma. J Clin Endocrinol Metab 2010;95:678-85.

18. Kvale WF, Roth G, Manger WM, et al. Pheochromocytoma. Circulation 1956;14:622-30.

19. Brunaud L, Nguyen-Thi PL, Mirallie E, et al. Predictive factors for postoperative morbidity after laparoscopic adrenalectomy for pheochromocytoma: a multicenter retrospective analysis in 225 patients. Surg Endosc 2016;30:1051-9.

20. Lentschener C, Baillard C, Dousset B, et al. Dogma is made to be broken. why are we postponing curative surgery to administer ineffective alpha adrenoreceptor blockade in most patients undergoing pheochromocytoma removal? Endocr Pract 2019;25:199.

21. Goldstein RE, O’Neill JA Jr, Holcomb GW III, et al. Clinical experience over 48 years with pheochromocytoma. Ann Surg 1999;229:755-64; discussion 764-6.

Cite this article as: Bihain F, Klein M, Nomine-Criqui C, Brunaud L. Robotic adrenalectomy in patients with pheochromocytoma: a systematic review. Gland Surg 2020;9(3):844-848. doi: 10.21037/gs-2019-ra-05 